ScIDice

\section{A Review On The Guidelines For Nutritional Assessment for HNC (Head and Neck Cancer) Patients Managed By Surgery}

Research Article

Shrikanth Muralidharan ${ }^{1 *}$, Arunkumar Acharya ${ }^{2}$, Pramila $\mathrm{M}^{3}$, Shanthi Margabandhu ${ }^{4}$, Seema Kamble ${ }^{5}$

${ }^{1}$ Reader, Department of Public Health Dentistry, Madha Dental College and Hospital, West Tambaram, Chennai, India.

${ }^{2}$ Professor and Head, Department of Public Health Dentistry, Navodaya Dental College and Hospital, Raichur, India.

${ }^{3}$ Professor and Head, Department of Public Health Dentistry, MR Ambedkar Dental College and Hospital, Bangalore, Karnataka, India.

${ }^{4}$ Public Health Dentist, Private Practitioner, Bangalore, Karnataka, India.

${ }^{5}$ Associate Professor, Department of Public Health Dentistry, Nair Dental College, Mumbai, India.

\title{
Abstract
}

There are a number of guidelines to assess the nutrition status of cancer cases. None of these guidelines are specifically Head and Neck (HNC) cancer related; except for the European guidelines. This paper reviews the different guidelines in nutrition for cancer cases and also their drawbacks.

Keywords: HNC; Cancer; Nutrition; Guidelines.

\section{Introduction}

The The 2019 ESPEN (European Society for Clinical Nutrition and Metabolism) guideline guidelines state that "early oral feeding is the preferred mode of nutrition for surgical patients". It is essential to consider any risk that may arise out of underfeeding during the post-operative recovery period. The report provides certain clinical guidelines which need to be followed especially while handling complicated cases like cancer. One essential recommendation is that of early enteral feeding. Its focus is on the concept of nutritional aspects of the Enhanced Recovery After Surgery (ERAS). The guidelines call for, "integration of nutrition into the overall management of the patient". Nutritional assessment and dietary recommendations was always a challenge for such cases [1]. Most of the guidelines have been generic in nature and not tailor made for Head and Neck Cancer (HNC) patients. Today newer guidelines are available that can serve to assess the nutritional requirements of $\mathrm{HNC}$. Dieticians are able to estimate and achieve the nutritional requirements for $\mathrm{HNC}$ patients through set equations provided for cancer patients.

\section{Guidelines For Nutritional Assessment In Cancer Patients}

Nutritional impacts occur due to side effects like taste and smell alterations, dysphagia, malabsorption, depression, anxiety, nausea [2]. Hence Nutritional intervention tends to help the patients gain some weight or at least maintain it and produce better surgical outcomes. Baseline assessment is important.

A number of screening tools are available which have been validated among cancer cases (Table 01) [3]. But these are not specific for HNC patients.

The Subjective global assessment (SGA) assesses nutritional status is based on the features of a history (weight change, dietary intake change, gastrointestinal symptoms that have persisted for greater than 2 weeks, and functional capacity) and physical examination (loss of subcutaneous fat, muscle wasting, ankle/sacral edema and ascites). Features are combined subjectively into an overall or global assessment in which patients are rated as being well nourished, moderately (or suspected of being) malnourished, or severely malnourished [4]. PGSGA combines: nutritional screening, assessment, interventional triage and monitors interventional success. Even though recommended in different guidelines, it is not a very oncology specific tool [4].

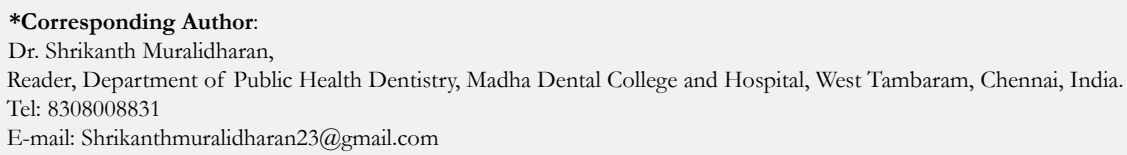

Copyright: Shrikanth Muralidharan ${ }^{\circ} 2021$. This is an open-access article distributed under the terms of the Creative Commons Attribution License, which permits unrestricted use, distribution and reproduction in any medium, provided the original author and source are credited. 
'MUST' is a five-step screening tool to identify adults, who are malnourished, at risk of malnutrition (undernutrition), or obese. It also includes management guidelines which can be used to develop a care plan [5]. The five steps are-

Step 1- Measurement of height and weight to get a BMI score.

Step 2- \% of weight loss (unplanned)

Step 3- Acute disease establishment and score.

Step 4-Addition of scores from 1, 2 and 3 to estimate the overall risk of malnutrition.

Step 5- Use guidelines for management and a care plan development.
A baseline assessment can assist us to identify the risk of deficiency of critical nutrients, help to formulate nutrition plan tailor made for specific individuals and monitor its impact at regular intervals or stages by comparing it with the previous assessment [6]. For those with different stages of treatment, more planning is necessary. It has to be monitored and considered separately. The same assessment may not hold true for all patients [7].

Table 02 shows the nutritional assessment criteria that is recommended currently [3].

A systematic nutritional risk screening (NRS) has to be consid-

Table 1. Screening tools in assessment of nutrition status among cancer patients.

\begin{tabular}{|c|c|}
\hline Tool & What the tool covers overall \\
\hline $\begin{array}{c}\text { The Subjective Global } \\
\text { Assessment (SGA) }\end{array}$ & $\begin{array}{c}\text { History and physical appearance is used to } \\
\text { assess the nutrition status of the patients. }\end{array}$ \\
\hline $\begin{array}{c}\text { The patient generated } \\
\text { - Subjective Global } \\
\text { Assessment (PGSGA)4 }\end{array}$ & $\begin{array}{c}\text { Modified SGA scale is purely patient response } \\
\text { oriented. }\end{array}$ \\
\hline $\begin{array}{c}\text { The Malnutrition } \\
\text { Screening }\end{array}$ & $\begin{array}{c}\text { Favoured by Patient-Generated Subjective } \\
\text { Global Assessment (PGSGA) }\end{array}$ \\
\hline $\begin{array}{c}\text { The Malnutrition } \\
\text { Universal } \\
\text { Screening Tool (MUST) }\end{array}$ & Mostly used in the United Kingdom. \\
\hline
\end{tabular}

Table 2. Nutritional assessment parameters recommended currently.

\begin{tabular}{|c|c|}
\hline \multirow{7}{*}{ Anthropometry } & Height \\
\hline & Weight / Weight History \\
\hline & Percentage weight change/loss \\
\hline & Body mass index; $<18.5 \mathrm{~kg} / \mathrm{m} 2$ suggests undernutrition \\
\hline & Skinfold thickness fat stores indication \\
\hline & Mid arm muscle circumference indicates lean tissue mass \\
\hline & Hand grip strength assesses muscle function \\
\hline \multirow{7}{*}{ Biochemistry } & Urea and electrolytes - indicate fluid status although can be disrupted by disease state and treatment \\
\hline & Albumin - not good indicator of nutritional status due to its long half-life (17-20 days) and it is affected by stress and sepsis \\
\hline & Pre-albumin - shorter half-life $2-3$ days but also affected by infection and stress \\
\hline & C-reactive protein - indication of acute phase response \\
\hline & Transferrin - affected by inflammation and infection \\
\hline & Total lymphocyte count - affected by infection \\
\hline & $\begin{array}{l}\text { Refeeding syndrome risk (abnormal sodium and fluid balance; altered glucose, protein, fat metabolism; deficiency of thymine, } \\
\text { magnesium and potassium) }\end{array}$ \\
\hline \multirow{3}{*}{$\begin{array}{l}\text { Clinical obser- } \\
\text { vation }\end{array}$} & Ability to chew and swallow (Dysphagia) \\
\hline & Clinical signs of weight loss e.g. ill-fitting dentures/clothing \\
\hline & Medical history which may affect nutritional intake e.g. coeliac disease, diabetes. \\
\hline \multirow{7}{*}{ Dietary history } & Review typical intake ( 24 hours recall,7diary), with attention being paid to: \\
\hline & Fluid intake \\
\hline & Changes in taste and texture \\
\hline & Reports of fullness \\
\hline & Length of time and effort taken to eat \\
\hline & Changes in appetite \\
\hline & Gastrointestinal function \\
\hline \multirow{4}{*}{$\begin{array}{l}\text { Calculation of } \\
\text { requirements }\end{array}$} & Energy: $22-25 \mathrm{kcal} / \mathrm{kg} /$ day x physical activity level. Can increase further if major complications (PENG, 2019). \\
\hline & Protein: $1.2-1.5 \mathrm{~g} / \mathrm{kg} /$ day for depleted of treatment complications. \\
\hline & Fluid: $30-35 \mathrm{ml} / \mathrm{kg} /$ day increases in infection and excessive fluid losses \\
\hline & Vitamins and minerals: As per recommended daily amounts unless considered deficient \\
\hline \multirow{2}{*}{$\begin{array}{l}\text { Proposed treat- } \\
\text { ment plan }\end{array}$} & Disease status, tumour site, (TNM Staging) \\
\hline & Nutritional implications of previous and current treatment plan \\
\hline \multirow{9}{*}{$\begin{array}{c}\text { Environmental } \\
\text { / Social infor- } \\
\text { mation }\end{array}$} & Alcohol intake \\
\hline & Smoking \\
\hline & Substance misuse \\
\hline & Social support \\
\hline & Dentition \\
\hline & Access to food and cooking skills \\
\hline & Social and financial circumstances \\
\hline & . Time taken to eat and drink \\
\hline & Patient perception of nutritional status \\
\hline
\end{tabular}


ered in all patients on hospital admission. An approach of only using the body weight as the lone indicator of malnourishment is ineffective since the epidemic of global obesity is on the rise and also there are other metabolic alterations which take place before appreciable change in the body weight [8].

\section{HNC Surgery and Malnourishment}

When there is an inadequate intake orally for more than 14 days, it is associated with a high mortality risk. Cancer patients who have a high nutritional risk must receive nutrition based support for 10 to 14 days before any major surgery [3]. In severe cases when possibility of difficulty in eating will persist for more than 7 days, enteral nutrition is always indicated perioperatively [3]. It is also recommended that in case where the food intake is anticipated to be inadequate for more than 10 days then enteral nutrition is recommended. Gastrostomy insertion is done in case feeding is essential via tube for more than 4 weeks [3]. Post- surgical swallowing problems are quite commonly encountered in $\mathrm{HNC}$ cases [9]. Post surgically, HNC cases undergo alterations in the short and long term swallowing pattern which subsequently requires enteral feeding [10]. With a compromised deglutition functioning, maintaining a nutrition balance is a big challenge in such cases [11]. A multicentric study reported that pain and scar in the region of surgery may dissuade the patients from consuming food normally. Those with more than $10 \mathrm{~kg}$ of weight loss post surgically were more dependent on mashed food [12]. There was only one study showing positively more cases $(60 \%)$ who were able to tolerate normal or soft diet and not dependent on tube feeding in less than 2 months of surgery. The authors state that, after a partial mandibulectomy procedure, a good reconstruction and early intervention for obtaining occlusion and normal functioning is the key to avoid nutrition associated complications in such surgeries [13]. So dietary plan should be part of the routine discharge summary and rehabilitative procedure for $\mathrm{HNC}$ cases undergoing surgery.

Guidelines For Estimating Nutritional Require-

\section{ments Among Cancer Patients}

An initial method of estimating Basal Metabolic Rate (BMR) for adults was proposed by Schofield in 1985 [14]. The equations are as follows-

The actual energy needed per day (ERR) can be calculated from the BMR after multiplying it by an activity factor as shown in Table 05-

In cancer cases, the Total Energy Expenditure (TEE) is also estimated using the formula-

TEE $=$ Resting Energy Expenditure $(\mathrm{REE})+$ activity-associated energy expenditure.

The drawback of using this formula is that it is not specific to HNC. REE is elevated in cases of cancer but in advanced cases due to fatigue and reduced physical activities lead to decrease in TEE [15]. Hence neither REE nor TEE can serve as an accurate prediction in HNC. Indirect calorimetric measurements serve as an accurate predictor for REE and is considered for all patients who are at- risk for malnourishment [16].

Another recommended target range to maintain or restore the lean body mass is $25-30 \mathrm{kcal} / \mathrm{kg} /$ day with 1.2 to 1.5 grams of protein $/ \mathrm{kg} /$ day. In severely depleted cases, higher protein supply may be required [17].

The Glasgow Prognostic Score (GPS), which includes the serum levels of $\mathrm{C}$ - reactive proteins as well as albumin, serves as a highly predictable tool for inflammation in cancer patients [18]. This rise in inflammation may be reactionary to the tumour growth and serves as a marker for overall survival of the patients [19].

Rayan and colleagues suggested that a retrospective analysis of the computed tomographic records can also help to detect the muscle mass loss and the fatty muscle infiltration [20].

\section{For Men (Table 03):}

Table 3. BMR estimation for adult male.

\begin{tabular}{|c|c|c|}
\hline Age & Equation (kcal/day) & SEE \\
\hline $18-30$ & $15.057 \times \mathrm{W}+692.2$ & 153 \\
\hline $30-60$ & $11.472 \times \mathrm{W}+873.1$ & 167 \\
\hline$>60$ & $11.711 \times \mathrm{W}+587.7$ & 164 \\
\hline
\end{tabular}

Where $-\mathrm{W}=$ Body weight in kilograms and SEE $=$ Standard error of estimation

For Women (Table 04):

Table 4. BMR estimation for adult female.

\begin{tabular}{|c|c|c|}
\hline Age & Equation (kcal/day) & SEE \\
\hline $18-30$ & $14.818 \times \mathrm{W}+486.6$ & 119 \\
\hline $30-60$ & $8.126 \times \mathrm{W}+845.6$ & 111 \\
\hline$>60$ & $9.082 \times \mathrm{W}+658.5$ & 108 \\
\hline
\end{tabular}

Where $-\mathrm{W}=$ Body weight in kilograms and SEE $=$ Standard error of estimation . 
Table 5. Activity factor for EER calculation.

\begin{tabular}{|c|c|c|c|c|}
\hline Number & Activity factor & Explanation & $\begin{array}{c}\text { Multiplication } \\
\text { factor for males }\end{array}$ & $\begin{array}{c}\text { Multiplication factor } \\
\text { for females }\end{array}$ \\
\hline 1. & Sedentary & $\begin{array}{c}\text { Sedentary is very physically inactive, inactive in } \\
\text { both work and leisure. }\end{array}$ & 1.3 & 1.3 \\
\hline 2. & Lightly active & $\begin{array}{c}\text { Lightly active means the daily routine includes } \\
\text { some walking, or intense exercise once or twice } \\
\text { per week. Most students are in this category. }\end{array}$ & 1.6 & 1.6 \\
\hline 3. & $\begin{array}{c}\text { Moderately } \\
\text { active }\end{array}$ & $\begin{array}{c}\text { Moderately active means intense exercise lasting } \\
\text { 20-45 minutes at least three times per week, or a } \\
\text { job with a lot of walking, or a moderate intensity } \\
\text { job. }\end{array}$ & 1.7 & 1.9 \\
\hline 4. & Very Active & $\begin{array}{c}\text { Very active means intense exercise lasting at least } \\
\text { an hour per day, or a heavy physical job, such as a } \\
\text { mail carrier or an athlete in training. }\end{array}$ & 2.1 & 2.2 \\
\hline 5. & Extremely \\
active & $\begin{array}{c}\text { Extremely active means an athlete on an unstop- } \\
\text { pable training schedule or a very demanding job, } \\
\text { such as working in the armed forces or shovelling } \\
\text { coal. }\end{array}$ & 2.4 & 2.9 \\
\hline
\end{tabular}

The latest ESPEN guidelines recommend the following 8-

1. Screen each patient's nutritional status early in the course of cancer treatment.

2. Identify signs or symptoms of anorexia, cachexia, and sarcopenia at the earliest.

3. Use of CT scan for detecting sarcopenia.

4. Use of specific biomarkers like CRP and albumin to assess cancer related systemic inflammation, e.g. CRP and albumin.

5. Use indirect calorimetry to estimate REE to personalize protein and energy needs.

6. Use nutrition and metabolic support as a vital part of cancer care.

7. Assess physical function routinely to monitor and guide physical rehabilitation.

Even though multiple methods have been suggested, these methods of estimation of nutrition are not very specific to the $\mathrm{HNC}$ cases. Hence a common consensus regarding their utilization in day-to-day practise is missing in literature.

Cancer and its treatment approaches therefore affect the nutritional status by altering the metabolic function and reduced food intake. Dietary supplements and fortified foods are used by patients as an adjunct to standard treatment. Evidence for international guidelines specifically for the type of $\mathrm{HNC}$ is missing. Hence one size fits all may not be true for such cases. Hence a common guideline, specifically for $\mathrm{HNC}$ cases separately is essential to assist the dieticians in formulation of diet counselling sessions and advisories in HNC patients.

Thus reduced nutritional status can be seen from the initial diagnosis which may exacerbate due to treatment related toxicities. Complications arising out of this may persist for a longer duration. Hence assessment of the nutritional status must be a part of the routine monitoring process for HNC patients. An early intervention can help to minimize the co morbidities associated with HNC treatment [21]. The European recommendations are the only set of guidelines that focus on HNC patients. Even though other guidelines are there, they are more general and not pertaining to a particular system affected or the specific therapy for cancer.

HNC patients are different from the other cancer types, due to the complex nature of the systems involved. Major chances of complications (local and systemic) can arise post HNC surgery like scar, pain, delayed wound healing, localized infection. Nutrition assessment of these patients is essential part of a multi-disciplinary approach to treatment. A failure of such an assessment can increase the complications and increase mortality rates. This assessment forms a part of pre as well as post-surgical period. Studies have reported quite contrasting outcomes with respect to the assessment techniques as well as the routes feeding. Different schools of thoughts can result in a neglected role of dietician in cancer therapy and also delay the physical as well as psychological healing of the patients; and also their quality of life, where diet is an important component. The recent ESPEN guidelines have been proposed for assessment for $\mathrm{HNC}$ cases, very little evidence is present on the feasibility of these guidelines to be used as an integral part of day to day practise.

Prior to the 2019 guidelines, specific assessment cut offs were not available for HNC patients undergoing any form of therapy. The assessment criteria were more generic than specific.At an institutional level, the ESPEN guidelines can serve to propose a better assessment of HNC patients and aid in more subjective and uniform evaluation of the nutritional intervention therapy.

Clinically the loss of weight or a low BMI usually indicate cachexia/ anorexia clinically [2]. Weight changes are not always associated with nutrition intake alone. BMI does account for the fluid loss like in dehydration or for a loss of body mass that makes a patient extremely lean [22]. Since BMI does not take into account the body composition, it at times can be misleading and false negative results may be generated [23]. There is always a possibility that cancer patients may present with normal body weight but sarcopenia may be severe in them. (I did not find any specific 
tool apart from BMI that was used for sarcopenia) So BMI cannot always be regarded as a lone gold standard for assessment sake 24. Serum albumin levels are changed in cancer cases; but these indicate the severity of any underlying inflammation rather than the severity of the disease itself. Their levels may not always be altered in all cancer cases due to the disease condition or the therapy provided alone [25]. The initial problem is that there is a complete lack of epidemiological data in terms of malnutrition related to HNC cancer [26]. Hence one does not always know the exact severity of the prevalence of malnutrition among HNC patients. The newer guidelines are an attempt to overcome this hurdle. There is a lack of uniform assessment pattern across the different hospitals curtailing to the needs of HNC patients; which was always a challenge. Taking an overall anthropometric measurement for all cases may not be feasible and is time consuming in the ward. Hence a total assessment of the body composition is also missed during the routine clinical examinations for HNC patients [27]. One size fits all rule also cannot be followed in HNC cases due to the complexity of the anatomical structures involved and also the different types of cancer and the combination of therapeutic options used for treatment purposes.

The PENG 2019 guidelines estimates the nutritional requirements for the cancer patients overall, but whether it is true for all those patients with different therapeutic interventions is yet not evident.A recent study reported that just meeting the minimum requirements as per the ESPEN guidelines may not attenuate loss of skeletal muscle in HNC patients [28]. The severity of the cancer, type of surgery and the post-surgical interventions should also be considered while the nutritional assessment is being done. End stage patients may need more interventions comparatively. Nutritional assessment should be therefore more holistic and not focus only on achieving a particular cut- off criteria. The nutritional assessment should also be part of the routine home based care.

In order to establish an accurate REE for patients, it is essential to understand the actual energy requirements by the patients. Only this can provide a better insight into an actual maintenance and overcome complications arising due to inadequate nutrition supply. This REE which is usually higher in cancer cases (more than $70 \%$ ) is influenced by a variety of factors such as age of the patients, gender, fat free mass and the total body mass [25]. An increase in the physical activity of the patients can further increase REE. So the calculations have to be custom made again per patient. One can measure the REE by using the Harris-Benedict equation(HB) or the indirect calorimetry (IC). A study by GraciaPeris and colleagues reported that using $\mathrm{HB}$ for BMR calculation is not always accurate in chemotherapy patients as compared to IC. So they suggest that IC is a gold standard technique than the $\mathrm{HB}$ equation [29]. In surgical cases of HNC, there are no literature reports if $\mathrm{HB}$ is a valid formula for estimation of BMR. Hence more studies are needed for stronger evidence. In case of advanced surgery, recovery phases may be prolonged along with the duration of hospital stay, testing the newer PENG guidelines for such cases is essential. Variability with respect to nutritional requirement and also the response to the nutritional therapy can be expected in relation to the type of tumour, surgical technique and also the age and gender of the patients. The nutritional assessment as per the new PENG guidelinesmay be different for cases which undergo chemo and radiotherapy also apart from surgery. Hence more evidence is required for case-based utilization of the guidelines. Different equations for assessment and cut off criteria may be required for cases which undergo only surgery and for cases which may require surgery and chemoradiotherapy.

BMI is the mainly used indicator for weight loss and indirectly correlates to malnourishment, using the same cut-off range for the non- cancer patients may require further review. All patients with cancer undergo alteration in the BMI. Hence a basic criterion for BMI classification for cancer patients and especially HNC cases is highly recommended. Therefore a patient, who already had a low BMI at the baseline, is more likely have low BMI score postsurgery. So the nutritional requirements should consider such a scenario while determining the outcomes.

Using the same assessment method for different categories of cancer is questionable. More evidence is needed for determining the sensitivity and specificity of the tool. If the newer guidelines are being used for estimation, then the chart for entries needs to be redrawn with a proper training and appraisal regarding the need to do so. The guidelines do not state any separate method for cases which need increased length of the hospital stay. Under such circumstances, a prolonged stay may be associated with better nutritional outcomes rather than home based care 30.Some of the equations previously used for nutritional assessments were generated by estimating the requirements in adult young participants. Hence this needs to be validated for its use in older individuals also.

\section{Recommendations}

1. Maintenance of food records is essential. Oncologists or nursing staffs may alter the food intake (quantity, nature) based on the request and condition of the patient. Example- a case undergoing glossectomy may need pureed food, since chewing and swallowing is a major challenge. So such specifications must be put on paper and additional help must be sought for the long term benefit of the patients.

2. The current guidelines do not take into account the different classes of BMI. But cancer specific cut offs for BMI are required with respect to BMI since it is a major part of the assessment criteria.

3. It is recommended to have a robust study with an idea case scenario where the sample size is large enough for statistically significant data. Also it needs to involve people with different races, have both male and female patients, and the cases matched for the type of cancer categorization. Performing an actual nutritional intervention using blinding can provide stronger evidence. This can help to provide more information about the assessment criteria specific for age, gender and also the type of cancer.

4. It may be ideal to have followed up of the cases to determine the weight gain, change in the body mass (from lean to healthy), REE and protein intake.

\section{References}

[1]. Mehanna H, Kong A, Ahmed SK. Recurrent head and neck cancer: United Kingdom National Multidisciplinary Guidelines. J Laryngol Otol. 2016 May;130(S2):S181-S190. Pubmed PMID: 27841130.

[2]. Moini K. Nutrition in Cancer Care. Physician Assistant Clinics. 2016 Jul 1;1(3):363-74.

[3]. Talwar B, Donnelly R, Skelly R, Donaldson M. Nutritional management in head and neck cancer: United Kingdom National Multidisciplinary Guidelines. J Laryngol Otol. 2016 May;130(S2):S32-S40. Pubmed PMID: 
27841109.

[4]. Jager-Wittenaar H, Ottery FD. Assessing nutritional status in cancer: role of the Patient-Generated Subjective Global Assessment. Curr Opin Clin Nutr Metab Care. 2017 Sep;20(5):322-329. Pubmed PMID: 28562490.

[5]. BAPEN. ' Malnutrition Universal Screening Tool ' MAG The 5 'MUST' Steps e c Sc or Sc or Sc. Published online 2011.

[6]. Rosenfeld RS. Diets and Diet Therapy: Enteral Nutrition. In: Encyclopedia of Food Security and Sustainability. Elsevier; 2019:119-130.

[7]. Baldwin C, Spiro A, Ahern R, Emery PW. Oral nutritional interventions in malnourished patients with cancer: a systematic review and meta-analysis. J Natl Cancer Inst. 2012 Mar 7;104(5):371-85. Pubmed PMID: 22345712.

[8]. Arends J, Bachmann P, Baracos V, Barthelemy N, Bertz H, Bozzetti F, et al. ESPEN guidelines on nutrition in cancer patients. Clin Nutr. 2017 Feb;36(1):11-48. Pubmed PMID: 27637832.

[9]. Govender R, Smith CH, Gardner B, Barratt H, Taylor SA. Improving swallowing outcomes in patients with head and neck cancer using a theory-based pretreatment swallowing intervention package: protocol for a randomised feasibility study. BMJ Open. 2017 Mar 27;7(3):e014167. Pubmed PMID: 28348190 .

[10]. van der Woerd B, Patel KB, Nichols AC, Fung K, Yoo J, MacNeil SD. Functional outcomes in early (T1/T2) supraglottic cancer: a systematic review. J Otolaryngol Head Neck Surg. 2018 Dec 18;47(1):76. Pubmed PMID: 30563567.

[11]. Crowder SL, Douglas KG, Frugé AD, Carroll WR, Spencer SA, Locher JL, et al. Head and neck cancer survivors' preferences for and evaluations of a post-treatment dietary intervention. Nutr J. 2019 Sep 10;18(1):57. Pubmed PMID: 31506077

[12]. Gellrich NC, Handschel J, Holtmann H, Krüskemper G. Oral cancer malnutrition impacts weight and quality of life. Nutrients. 2015 Mar 27;7(4):2145-60. Pubmed PMID: 25825828.

[13]. Mizukami T, Hyodo I, Fukamizu H, Mineta H. Reconstruction of lateral mandibular defect: a comparison of functional and aesthetic outcomes of bony reconstruction vs soft tissue reconstruction - long-term follow-up. Acta Otolaryngol. 2013 Dec;133(12):1304-10. Pubmed PMID: 24245700.

[14]. Schofield WN. Predicting basal metabolic rate, new standards and review of previous work. Hum Nutr Clin Nutr. 1985;39 Suppl 1:5-41. Pubmed PMID: 4044297.

[15]. Purcell SA, Elliott SA, Baracos VE, Chu QSC, Sawyer MB, Mourtzakis $\mathrm{M}$, et al. Accuracy of Resting Energy Expenditure Predictive Equations in Patients With Cancer. Nutr Clin Pract. 2019 Dec;34(6):922-934. Pubmed PMID: 31347209.

[16]. Purcell SA, Elliott SA, Baracos VE, Chu QS, Prado CM. Key determinants of energy expenditure in cancer and implications for clinical practice. Eur J Clin Nutr. 2016 Nov;70(11):1230-1238. Pubmed PMID: 27273068.

[17]. Bozzetti F. Tailoring the nutritional regimen in the elderly cancer patient. Nutrition. 2015 Apr;31(4):612-4. Pubmed PMID: 25770330.

[18]. Proctor MJ, Talwar D, Balmar SM, O'Reilly DS, Foulis AK, Horgan PG, et al. The relationship between the presence and site of cancer, an inflammation-based prognostic score and biochemical parameters. Initial results of the Glasgow Inflammation Outcome Study. Br J Cancer. 2010 Sep 7;103(6):870-6. Pubmed PMID: 20717110

[19]. He L, Li H, Cai J, Chen L, Yao J, Zhang Y, et al. Prognostic Value of the Glasgow Prognostic Score or Modified Glasgow Prognostic Score for Patients with Colorectal Cancer Receiving Various Treatments: a Systematic Review and Meta-Analysis. Cell Physiol Biochem. 2018;51(3):1237-1249. Pubmed PMID: 30481755.

[20]. Ryan AM, Power DG, Daly L, Cushen SJ, Ní Bhuachalla Ė, Prado CM. Cancer-associated malnutrition, cachexia and sarcopenia: the skeleton in the hospital closet 40 years later. Proc Nutr Soc. 2016 May;75(2):199-211. Pubmed PMID: 26786393.

[21]. Messing BP, Ward EC, Lazarus C, Ryniak K, Kim M, Silinonte J, et al. Establishing a Multidisciplinary Head and Neck Clinical Pathway: An Implementation Evaluation and Audit of Dysphagia-Related Services and Outcomes. Dysphagia. 2019 Feb;34(1):89-104. Pubmed PMID: 29922848.

[22]. Marian M, Roberts S. Clinical nutrition for oncology patients. Jones \& Bartlett Publishers; 2010 Oct 25.

[23]. Rock CL, Doyle C, Demark-Wahnefried W, Meyerhardt J, Courneya KS, Schwartz AL, et al. Nutrition and physical activity guidelines for cancer survivors. CA Cancer J Clin. 2012 Jul-Aug;62(4):243-74. Pubmed PMID: 22539238.

[24]. Rattray M, Desbrow B, Roberts S. Comparing nutritional requirements, provision and intakes among patients prescribed therapeutic diets in hospital: An observational study. Nutrition. 2017 Jul-Aug;39-40:50-56. Pubmed PMID: 28606570.

[25]. Alshadwi A, Nadershah M, Carlson ER, Young LS, Burke PA, Daley BJ Nutritional considerations for head and neck cancer patients: a review of the literature. J Oral Maxillofac Surg. 2013 Nov;71(11):1853-60. Pubmed PMID: 23845698.

[26]. Virizuela JA, Camblor-Álvarez M, Luengo-Pérez LM, Grande E, ÁlvarezHernández J, Sendrós-Madroño MJ, et al. Nutritional support and parenteral nutrition in cancer patients: an expert consensus report. Clin Trans Oncol. 2018 May;20(5):619-629. Pubmed PMID: 29043569.

[27]. Andreoli A, De Lorenzo A, Cadeddu F, Iacopino L, Grande M. New trends in nutritional status assessment of cancer patients. Eur Rev Med Pharmacol Sci. 2011 May;15(5):469-80. Pubmed PMID: 21744742.

[28]. McCurdy B, Nejatinamini S, Debenham BJ, Álvarez-Camacho M, Kubrak C, Wismer WV, et al. Meeting Minimum ESPEN Energy Recommendations Is Not Enough to Maintain Muscle Mass in Head and Neck Cancer Patients. Nutrients. 2019 Nov 12;11(11):2743. Pubmed PMID: 31726711.

[29]. García-Peris P, Lozano MA, Velasco C, de La Cuerda C, Iriondo T, Bretón $\mathrm{I}$, et al. Prospective study of resting energy expenditure changes in head and neck cancer patients treated with chemoradiotherapy measured by indirect calorimetry. Nutrition. 2005 Nov-Dec;21(11-12):1107-12. Pubmed PMID: 16308133.

[30]. Van Nes MC, Herrmann FR, Gold G, Michel JP, Rizzoli R. Does the mini nutritional assessment predict hospitalization outcomes in older people? Age Ageing. 2001 May;30(3):221-6. Pubmed PMID: 11443023. 